\title{
The cost to society of smoking cessation
}

\author{
David Cohen, Garry Barton
}

University of Glamorgan Business School, Pontypridd, Mid Glamorgan CF37 1DL, UK

Introductory article

The health care costs of smoking

JJ Barendregt, L Bonneux, and PJ van der Maas

Background. Although smoking cessation is desirable from a public health perspective, its consequences with respect to health care costs are still debated. Smokers have more disease than nonsmokers, but nonsmokers live longer and can incur more health costs at advanced ages. We analyzed health care costs for smokers and nonsmokers and estimated the economic consequences of smoking cessation. Methods. We used three life tables to examine the effect of smoking on health care costs-one for a mixed population of smokers and nonsmokers, one for a population of smokers, and one for a population of nonsmokers. We also used a dynamic method to estimate the effects of smoking cessation on health care costs over time. Results. Health care costs for smokers at a given age are as much as 40 percent higher than those for nonsmokers, but in a population in which no one smoked the costs would be 7 percent higher among men and 4 percent higher among women than the costs in the current mixed population of smokers and nonsmokers. If all smokers quit, health care costs would be lower at first, but after 15 years they would become higher than at present. In the long term, complete smoking cessation would produce a net increase in health care costs, but it could still be seen as economically favorable under reasonable assumptions of discount rate and evaluation period. Conclusions. If people stopped smoking, there would be a savings in health care costs, but only in the short term. Eventually, smoking cessation would lead to increased health care costs. (N Engl J Med 1997;337:1052-7)

Smoking related diseases cost the British National Health Service (NHS) somewhere between $f 1.4$ billion and $£ 1.7$ billion every year. ${ }^{1}$ It is hardly surprising, and $\AA_{1.7}$ billion every year. ${ }^{1}$ It is hardly surprising, therefore, that reductions in these health care costs
should be highlighted as a major benefit of smoking cessation. However, non-smokers live longer than smokers. In the USA $78 \%$ of male non-smokers are still alive at the age of 70 compared with $57 \%$ of smokers. At the age of 80 the figures are $50 \%$ and $21 \%$, respectively. ${ }^{2}$ Non-smokers thus im Non-smokers thus citizens who smoke. This has led to much recent research into who has the greater lifetime health care costs, the
smoker or the non-smoker? In the introductory article smoker or the non-smoker? In the introductory article
Barendregt and colleagues conclude that, despite the short term savings to society from smokers quitting, the long term effect will be a net increase in health care costs. $^{2}$

The public health policy implications of this conclusion require several additional issues to be addressed, including the key question - so what? Barendregt and colleagues quite rightly point out that the primary objective of health policy is not to save money, and therefore evaluation of policy measures cannot be on the basis of whether or not they produce net resource savings: “. . . in formulating public health policy, whether or not smokers impose a net financial burden ought to be of very limited importance" (page 1057). A more appropriate health policy objective is to increase life years and improve health related quality of life. What matters, therefore, is how the cost of achieving these health gains through smoking cessation interventions compares with the cost of achieving them by other means.

It was not the intention of the Barendregt study, nor is it the intention of the present review, to address that question. Reviews of the cost effectiveness of smoking cessation are available elsewhere. ${ }^{34}$ Here, the focus is on the cost to society of smoking cessation. We shall address this by critically examining the approach and assumptions of the Barendregt study with respect to health care costs of smoking, and by considering the wider economic implications of changing smoking habits, since the financial costs of smoking are not confined to health service resource use.

Does the introductory article underestimate the health care costs of smoking?

The estimate which Barendregt and colleagues provide for the lifetime health care costs of smokers and nonsmokers is based on the incidence, prevalence, and 
mortality associated with five major categories of smoking related diseases, and the relevant "rate ratios" (differences in frequency of disease between smokers and non-smokers) derived from the literature. These five major categories comprised: heart disease, stroke, lung cancer, a heterogeneous group of other cancers, and chronic obstructive pulmonary disease.

This approach is a wholly appropriate one which will capture the bulk of the extra health care costs of smoking. There are, however, several reasons why such an approach will understate the true extra costs of smoking. These we shall discuss further.

HEALTH CARE COSTS OF OTHER SMOKING RELATED DISEASES

While accepting that the five categories of disease used in the Barendregt study represent the bulk of smoking related morbidity and mortality, and hence the majority of health care costs, the list of other diseases in which smoking has been implicated is long and growing. Omission of these other smoking induced diseases thus understates the true health care costs of smoking. For derstates the true health care costs of smoking. For
example, there is mounting evidence of a relationship example, there is mounting evidence of a relationship
between smoking and the incidence of cataract, with a
relative risk for smokers of more than 20 cigarettes per relative risk for smokers of more than 20 cigarettes per day as high as $2.16 .^{56}$ Given that over 1.1 million cataract operations were performed in the USA in 1989 and that reimbursement for these procedures account for approximately $12 \%$ of the Medicare budget, ${ }^{7}$ the extent of the extra health care costs in this area is clearly considerable.

Evidence of an increased risk of hip fractures in smokers has also been reported. ${ }^{8} \mathrm{~A}$ recent meta-analysis suggests that bone density diminishes after the age of 50 leading to an increased risk of hip fracture for curren smokers of $17 \%$ at age $60,41 \%$ at age 70 , and $108 \%$ at age 90 . Again, given the high volume of hip fracture operations this translates into considerably increased operations this tran

HEALTH CARE COSTS OF DELAYED RECOVERY FROM NON-SMOKING RELATED CONDITIONS

There is evidence that smoking inhibits recovery from a number of non-smoking related conditions. It has been shown to be a risk factor for increasing the time patients spend in a post-anaesthesia care unit (PACU) following a wide range of surgical procedures. ${ }^{10}$ Thirty eight percent of non-smokers were discharged from the PACU less than one hour after admission compared with only $23 \%$ of smokers. Similar problems have been reported for delayed wound healing. ${ }^{11}$ They have been explained by nicotine, carbon monoxide, and hydrogen cyanide undermining expeditious wound repair.

HEALTH CARE COSTS OF PASSIVE SMOKING

The Barendregt study assumed that smoking induced disease is confined to smokers. This ignores mounting evidence of the health effects of passive smoking on non-smokers. In the USA the Environment Pro Agency (EPA) attributed 53000 deaths of non-smokers each year to passive smoking. ${ }^{12}$

The increased risks of lung cancer and ischaemic heart disease from passive smoking have both been subject to recent meta-analyses. From 37 identified studies it was estimated that living with someone who smokes increases the risk of lung cancer by $26 \%$, after adjustment for bias and dietary factors. ${ }^{9} \mathrm{~A}$ subsequen report estimated this risk enhancement to be even higher at $53 \%$ for Russian women whose husbands smoke. ${ }^{13}$ Similarly, a 23\% increased risk of ischaemic heart disease has been shown for lifelong non-smokers who live with smokers rather than non-smokers. ${ }^{14}$ Passive smoking is also associated with a $25 \%$ increase in the risk of acute also associated with
respiratory illness.

Children whose parents smoke have an increased risk of a wide range of respiratory illnesses. ${ }^{16-20}$ In the USA an EPA report ${ }^{21}$ estimated that the respiratory health of between 200000 and one million asthmatic children is worsened by exposure to environmental tobacco smoke. An excess of hospital attendances (which were attributed to environmental tobacco smoke) suggested that children of smoking curred health expenditures for respiratory illness at a rate more than two and a half times that of children of non-smoking mothers. ${ }^{22}$ It could be, however, that socioeconomic factors associated with smoking had also played a role. The direct annual medical expenditure for early childhood respiratory illness attributable to maternal smoking totalled \$661 million for all children under the age of six. In Hong Kong the cost per child of general practice consultations for cough, phlegm or wheeze was $14 \%$ higher for children living in a one smoker home, and $25 \%$ for two or more smokers, compared with no smokers in the home. ${ }^{23}$

HEALTH CARE COSTS OF BIRTH OUTCOMES DUE TO SMOKING WHILST PREGNANT

In a series of meta-analyses DiFranza and $\mathrm{Lew}^{24}$ estimated that each year in the USA smoking during pregnancy is responsible for 19000-141000 abortions, 32 000-61 000 low birth weight babies, 14 000-26000 admissions to neonatal intensive care units (NICU), 1900-4800 deaths from perinatal disorders, and 12002200 deaths from sudden infant death syndrome. The wide ranges are due to the uncertainty about the proportion of women who smoke whilst pregnant and the fact that many estimates have not been adjusted to take account of confounding factors.

Costs of NICU cases are particularly high, and recent US figures suggest that smoking is responsible for $15 \%$ of all preterm births and 20-30\% of all infants with low birth weight that require NICU admission. ${ }^{25} \mathrm{Li}_{\text {et }} \mathrm{l}^{26}$ have estimated the average cost per NICU admission at between $\$ 5213$ and $\$ 10306$, but argued that this
may overstate the cost attributable to smoking as the may overstate the cost attributable to smoking as the
impact of smoking on birthweight is greater in the impact of smoking on birthweight is greater in the are higher. Their adjusted net incremental cost per low birthweight baby due to smoking ranged from $\$ 4256$ 8640 . The extra health care costs of babies who survive but have long term health care needs due to their initial low birthweight would have to be added to this. Whichever estimates are used, it is apparent that the costs calculated by Barendregt and colleagues omit major health care costs attributable to smoking.

HEALTH CARE COSTS DUE TO OTHER HEALTH RELATED CHARACTERISTICS OF SMOKERS

There is an implicit assumption in the Barendregt dynamic model that the higher morbidity and mortality among smokers is due entirely to their smoking. There is considerable evidence that demographic and behavioural differences between smokers and non-smokers might partly explain health related differences between the two groups. For example, smokers tend to be of 
lower socioeconomic status, ${ }^{27}$ have a lower level of education, ${ }^{28}$ take less exercise, ${ }^{29}$ eat a less healthy diet, ${ }^{30}$ and consume more alcohol ${ }^{2831}$ than non-smokers. All of these are associated with higher morbidity and mortality and, taken together, suggest that a population health care costs than a population of non-smokers, even in the long term. In this respect, then, the in troductory article may have overestimated the true health care cost of smoking.

\section{Other (non-health care) costs of smoking}

While the question addressed in the Barendregt study was limited to differences in lifetime health care costs between smokers and non-smokers, there are other costs (and benefits) which smoking imposes on the economy. There is no reason in principle why these costs should be regarded as any less relevant to society than health care costs.

COSTS TO INDUSTRY FROM SMOKING RELATED ABSENCES Smoking is a major cause of sickness absence which imposes major costs on industry from lost productivity. In the UK approximately 50 million working days are lost each year due to smoking, ${ }^{32}$ valued at $£ 1710$ million. This is more than the estimated cost of smoking to the NHS.

US smokers are absent from work approximately 6.5 days more per year than non-smokers. ${ }^{33}$ Costs of lost productivity of persons disabled by smoking related diseases and forfeited earnings of those dying prediseases and forfeited earnings of those dying pre-
maturely of such diseases have been put at $\$ 47$ billion maturely of such diseases have been put at $\$ 47$ billion
per year. ${ }^{34}$ To this should be added another $\$ 8.6$ billion per year. ${ }^{34}$ To this should be added another $\$ 8.6$
of lost productivity due to passive smoking. ${ }^{35}$

The processes which give rise to absence from the workplace, however, are complex. The simple observation of higher rates of absence among smokers may therefore be in to establish a causal connection between smoking and absence from work. ${ }^{36}$ In a recent study Bush and Wooden ${ }^{37}$ showed that morbidity alone cannot fully explain the higher sickness absence of smokers, and speculated that some behavioural characteristics associated with smokers may be partly responsible. Nevertheless, even after controlling for numerous health indicators (alcohol, exercise, weight), job characteristics (employment status, hours worked, income, occupation), and demographic characteristics (age, sex, ethnicity, marital status, education, place of residence), the study still showed smoking status to be highly correlated with absence from work

Although it would be wrong to suggest that the whole cost of the higher absenteeism of smokers is due to their smoking induced morbidity, the further cost to society from smoking is bo Even if lifetime health care costs are greater for non-smokers than smokers (as Barendregt and colleagues suggest), the difference is more than offset by the gain in lifetime work productivity. This suggests that the economic benefit of smoking cessation will be positive (and large) regardless of the net effect on health care costs.

OTHER COSTS OF SMOKING

In the UK fires caused by cigarette smoking have been estimated to cost $£ 20$ million per annum. ${ }^{38}$ In the USA such fires are the leading cause of civilian fire death (2300 deaths per year) with an additional 5000 injuries per year. ${ }^{39}$ In addition to the health care costs of treating burn victims, property damage from fires caused by cigarettes has been valued at $\$ 552$ million per year.

\section{Beneficial economic effects of smoking}

Any assessment of the economic costs of smoking, and the potential economic benefits of cessation, would be incomplete unless it also took account of the positive economic effects of smoking and the consequences on these of smoking cessation. Smoking has also been reported to have beneficial effects on a wide range of medical conditions; the evidence has been reviewed by Baron. ${ }^{40}$ Here we focus solely on the potential benefits to the economy.

GOVERNMENT REVENUE FROM TOBACCO DUTY

Although strictly tobacco duty is a transfer payment rather than a true economic cost ${ }^{41}$ it is a major source of government revenue and any reduction in smoking would involve a significant loss to the Exchequer. In 1994, 460 million cigarettes were consumed in the UK 1994,460 million cigarettes were consumed in the UK
representing a spending of $£ 10017$ million. Of this the representing a spending of $£ 10017$ million. Of this the
government received duty of $£ 8463$ million $(80 \%$ of retail price). This represents about $10 \%$ of total Customs and Excise revenue and $3 \%$ of total government direct and indirect tax revenue..$^{42}$ Revenue from tobacco duty is considerably higher than the costs smoking imposes on society.

EMPLOYMENT IN THE TOBACCO AND DEPENDENT INDUSTRIES

Employment in the UK in the tobacco industry has been falling over recent decades. ${ }^{42}$ The economic consequences of a further loss of jobs is commonly brought to society's attention by the tobacco industry, and there are many other jobs which depend indirectly on smoking, including the retail and wholesale trade sectors.

While reductions in smoking prevalence will reduce jobs in the tobacco industry, this will not necessarily lead to an overall increase in unemployment. Much of the money which smokers currently spend on cigarettes will be spent elsewhere, increasing the demand for other goods and servic other industries. The extent of this effect depends on the spending patterns of former smokers. McNicoll and Boyle $^{43}$ estimated that a complete cessation of cigarette purchasing by the citizens of Glasgow would bring net benefits to the Scottish economy. Each $£ 1$ million reduction in cigarette expenditure would lead to a net increase in Scottish output of $£ 1.1$ million and a net increase in Scottish employment of 64 jobs.

A similar result was found by Buck et $a l^{42}$ who estimated the effect of a $40 \%$ reduction in smoking - the target set by the 1992 UK policy document "The Health of the Nation" ${ }^{44}$ Using a reasonable set of assumptions they estimated that the reduction in spending on tobacco would result in a net overall increase of 150000 jobs in the UK.

Even in tobacco growing countries the consequent gain in jobs in other industries may exceed the loss experienced in the tobacco industry as tobacco consumption diminishes. In the USA Warner $e t a l^{45} \mathrm{com}-$ pared the south-east tobacco growing region with eight non-tobacco regions and estimated that, with no spending on tobacco, the south-east would lose 222000 jobs but this would be compensated by a gain of 355000 jobs throughout the rest of the country (assuming gov- 


\section{LEARNING POINTS}

* Smokers impose costs on society for health services from smoking related diseases.

* Non-smokers live longer and thus impose higher costs on society in old age.

* Whether or not the short term health care cost savings from smoking cessation outweigh the long term extra costs of a larger elderly population depends on the chosen "discount rate".

* The cost of smoking to society includes much more than health care costs, and the cost of lost productivity at work from smoking related sickness absence is greater than the health care cost of smoking related illness.

* While cost saving is a benefit, the principal benefit of smoking cessation is the health gain associated with a longer living, healthier population.

* From a policy perspective, what matters is how cost effective are smoking cessation interventions compared with other preventive and curative interventions.

ernment replaces lost revenue by increasing income $\operatorname{tax})$

\section{STATE PENSIONS}

Shorter life expectancy also means reduced expenditure on pensions. As with tobacco duty, pensions are transfer payments rather than true costs ${ }^{41}$ but do nevertheless represent significant losses to the Exchequer. Manning et $a l^{46}$ have estimated that every pack of cigarettes smoked decreases life expectancy by 137 minutes and pension costs by $\$ 1.82$.

Effects of the passage of time

Assessing the costs to society of smoking-and hence the benefits to society of non-smoking - is complicated by the time dimension in several ways. Firstly, as $\mathrm{Ba}$ rendregt and colleagues point out, there will be a considerable time lag between smoking cessation and the consequent beneficiat effects on morbidity and mortality. The current health care costs of non-smokers cannot therefore be used as an estimate of what would happen if existing smokers quit. They deal with this by using a dynamic model based on a series of linked life tables for different points in time where population size, disease incidence, and associated mortality in any period are determined by the relevant values for the previous period.

Secondly, a basic economic principle is that society is not indifferent about the timing of costs and benefit, preferring benefits sooner and costs later. ${ }^{41}$ Economists thus adjust future costs and benefits to "present values" by applying an appropriate "discount factor". While there is universal agreement among economists of the need to discount future monetary costs and benefits (the issue of discounting intangible benefits such as life years remains controversial ${ }^{47}$ ), there is no similar agreement on the appropriate rate to use. In the UK the Treasury currently specifies a discount rate of $6 \%$ for public sector evaluations for consistency.

Barendregt and colleagues point out that "having all smokers quit becomes economically attractive when the future benefits are larger than the future costs. (page1056) but this will depend crucially on what dis- count rate is applied. The health care costs of nonsmokers living longer are further in the future than the smoking related health care costs of smokers. Quitting therefore produces early cost savings and late cost increases. In the Barendregt analysis the "break even" point occurs 26 years after the population of ste quits if a zero discount rate is applied. At a rate of 3\% the break even time rises to 31 years, at $5 \%$ it rises to 37 years, and at $10 \%$ it is not reached by 50 years, and may never be reached at all.

Their response to this is to argue that "discounting should not be applied in a descriptive context, such ts" (page 1056). This view is untenable and presenting cost saving data in nominal (undiscounted) figures is highly misleading. Smoking affects the claims on health care resources such as doctor time, medication, and hospital beds. The monetary value of these resources cannot be expressed independently of time unless supported by an argument of social indifference-which is indefensible on theoretical grounds and inconsistent with observed behaviour. A fial complicating relates to the rate at which smoking cessation can realistically be expected to occur. While total population abstinence may be an ultimate policy goal, it is inconceivable that all smokers would quit simultaneously. The effects on all the above economic costs depend critically on the rate at which smokers cease to smoke.

Conclusions

The methodology of the Barendregt study was essentially sound. It accounted for all the main sources of smoking related health care costs but it was not fully comprehensive. 'The authors' conclusion that the lifetime costs for non-smokers are higher than those for rates. Rates above $4.5 \%$ (cf UK Treasury discount rate of $6 \%$ ) produce the opposite result. Furthermore, the costs to society of smoking are considerably wider than those of health care addressed by the Barendregt study. This consequently underestimated the potential benefits of total smoking cessation.

From a policy perspective, however, none of this really matters much. What does matter is what can be done 
to reduce the costs to society of smoking-and at what cost? This involves the economic evaluation of smoking cessation policies, programmes, and interventions. Reviews of the cost effectiveness of smoking cessation measure ${ }^{34}$ all suggest that, on economic ther efforts to produce health gains through smoking cessation are fully justified.

1 Health Education Authority. Cost effectiveness of smoking interventions. 2 Barendregt JJ, Bonneux I, van der Maas PJ. The health care costs of smoking. N Engl I M Med 1997;337:1052-7.

therapies: A review of economic appraisals. PharmacoEconomics 1993; 4:331-44.

4 Buck $\mathrm{D}$. The cost effectiveness of smoking cessation interventions: what

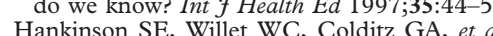

cigarette smoking and risk of cataract surgery in women. $¥ A M A 1992$ 268:994-8.

Christen WG, Manson JE, Seddon JM, et al. A prospective study of
cigarette smoking and risk of cataract surgery in men. $\mathscr{F} M A A 1992$ 268:989-93.

7 Editorial. Does smoke get in your eyes? YAMA 1992;268:1025-6. Br Med Bull 1996;52:3-11.
Hackshaw AK, Law MR, Wald NJ. The acted cancer and environmental tobacco smoke. $B M \mathcal{F}$ 1997;315:980-8.
andin Am F Med 1992;93:1A-32S. 12 Silverstein P. Smoking and wound healing. Am 7 Med 1992;93:1A-37S. assessment of lung cancer in adults and respiratory disorders in
aldren. External Review Draft Report No. EPA-600-6-90006A,

Zaridze D, Maximovitch D, Zemlyanaya G, et al. Exposure to enwomen from Moscow, Russia. Int 7 Cancer 1998; 75:335-8 14 Law MR, Morris JK, Wald NJ. Environmental tobacco smoke exposure
and ischaemic heart disease: an evaluation of the evidence $B M Y 1997$; and ischaemic heart disease: an evaluation of the evidence BMf 1997,

$1996 ; 52: 22-43$.
16 Evans D, Levison MJ, Feldman $\mathrm{CH}$, et al. The impact of passive Evans D, Levison MJ, Feldman $\mathrm{CH}$, et al. The impact of passive
smoking on emergency room visits of urban children with cancer. $A m$ Rev Respir Dis 1987;135:567-7

17 Couriel JM, Passive smoking and the health of children. Thorax 1994 18 Richards GA, Terblance APS, Theron AJ, et al. The health effects of passive smoking in adolescent children. S Afr Med $¥$ 1996;86:639-42. passive smoking in adolescent children. Afr Med fina 196;86:639-42
Margolis PA, Keyes LL, Greenberg RA, et al. Urinary cotinine and parent history as indicators of passive smoking and predictors of lowe Stoddart JJ, Miller T. I

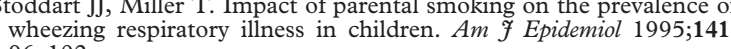

21 Environmental Protection Agency. Respiratory health effects of passive smoking: lung cancer and other disorders. Office of Health and Enental Assessment, Washington, DC: 1992

22 Stoddard JJ, Gray B. Maternal smoking and medical expenditures fo 23 Peters J McCade CI Hedley AJ, et al Economic b:205-9. vironmental tobacco smoke on Hong Kong families: scale and impact. f Epidemiol Community Health 1998;52:53-8.

24 DiFranza JR, Lew RA. Effect of maternal cigarette smoking on preg1995; 40:385-94 25 Aligne CA, Stoddard JJ. Tobacco and children: an economic evaluation
of the medical effects of parental smoking. Arch Pediatr Adolesc Med
1997;151:648-53. $\mathrm{Li} \mathrm{CQ}$, Windsor RA, Hassan M. Cost difference between low birthweight
attributable to smoking and low birthweight for all causes. Prev Med

1994;23:28-34.
Marmot M. Inequality, deprivation and alcohol use. Addiction 1997; Jarvis J. A profile of tabacco smoking. Addiction 1994;89:1371-6. Shoenborn CA, Boyd GM. Smoking and other tobacco use. Vital and Hyattsville, Maryland, National Centre for Health Statistics, 1989 , Margetts BM, Jackson AA. Interactions between people's diet and thei smoking habits: the dietary and Doll R, Peto R, Wheatley

years observation on male British doctors. BMf 1994;309:901-11. 32 Townsend J. Social cost, externalities and tobacco taxation in UK 33 Lesmes GR. Corporate health care costs and smoke free environments. Am $\mathcal{F}$ Med 1992;93(Suppl 1A):1A-48S-1A-54S.
34 MacKenzie TD, Bartecchi CE, Schrier RW. The human costs of tobacco use. $N$ Engl F Med 330:975-80.
. issues. Am F Med 1992;93(Suppl 1A):1A-38S-1A-42S.

6 Ault RW, Ekelund RB, Jackson JD, et al. Smoking and absenteeism. 37 Bush R, Wooden M. Smokin

evidence. Soc Sci Med 1995;41:437-46sence from work: Australian Action on Smoking and Health. Fact Sheet No 3: Economics of 39 McGuire A. Cigarettes and fire deaths. NY State f Med 1983;83:1229. 40 Baron JA. Beneficial effects of nicotine and cigarete smoking; the real,

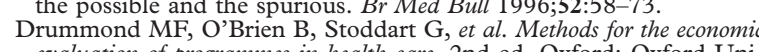
evaluation of programmes in health care. 2nd ed. Oxford: Oxford University Press, 1997.
Buck D, Godfrey C, Raw M, et al. Tobacco and jobs: the impact of
reducing consumption on employment in the UK. University of York,

Centre for Health Economics, York: 1995 .
43 McNicoll I, Boyle S. Regional economic impact of a reduction of
resident expenditure on cigarettes: a case study of Glasgow. Applied resident expenditure on cigarettes: a case study of Glasgow. Applied
Economics 1992;24:291-6. 44 Department of Health. The health of the nation. London: HMSO, 1992. Warner KE, Fulton GA, Nicolas $\mathrm{P}$, et al. The economic implications of
tobacco product sales for the regional economies of the United States. IAMA 1996;275:1241-6. 46 Manning WG, Keeler EB, Newhouse JP, et al. The taxes of s
smokers and drinkers pay their way? IAMA 1989;261:1604-9. 47 Gyrd-Hansen D, Sogaard J. Discounting life-years: whither time pref- 